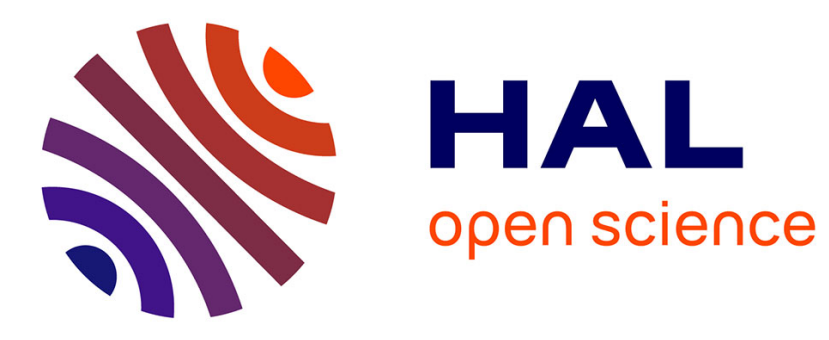

\title{
When Knowledge Follows Blood
}

\author{
Matthieu Salpeteur, Hanoz Patel, Andrea Balbo, Xavier Rubio-Campillo, \\ Marco Madella, P Ajithprasad, Victoria Reyes-García
}

\section{To cite this version:}

Matthieu Salpeteur, Hanoz Patel, Andrea Balbo, Xavier Rubio-Campillo, Marco Madella, et al.. When Knowledge Follows Blood: Kin Groups and the Distribution of Traditional Ecological Knowledge in a Community of Seminomadic Pastoralists, Gujarat (India). Current Anthropology, 2015, 56 (3), pp.471-483. 10.1086/681006 . halshs-01973769

\section{HAL Id: halshs-01973769 \\ https://shs.hal.science/halshs-01973769}

Submitted on 8 Jan 2019

HAL is a multi-disciplinary open access archive for the deposit and dissemination of scientific research documents, whether they are published or not. The documents may come from teaching and research institutions in France or abroad, or from public or private research centers.
L'archive ouverte pluridisciplinaire HAL, est destinée au dépôt et à la diffusion de documents scientifiques de niveau recherche, publiés ou non, émanant des établissements d'enseignement et de recherche français ou étrangers, des laboratoires publics ou privés. 


\section{When Knowledge Follows Blood}

\author{
Kin Groups and the Distribution of Traditional \\ Ecological Knowledge in a Community \\ of Seminomadic Pastoralists, Gujarat (India)

\section{Salpeteur, H. Patel, A. L. Balbo, X. Rubio-Campillo,} \\ M. Madella, P. Ajithprasad, and V. Reyes-García
}

Institut de Ciència i Tecnologia Ambientals, Universitat Autónoma de Barcelona (ICTA-UAB), Edifici Z Campus de la UAB, Bellaterra, 08193 Barcelona, Spain (matthieusalpeteur@hotmail.com) (Salpeteur and ReyesGarcía)/Maharaja Sayajirao University of Baroda, 390002 Vadodara, Gujarat, India (Patel and Ajithprasad)/ Complexity and Socioecological Dynamics (CaSEs), Universitat Pompeu Fabra, c/ Ramon Trias Fargas 25-27, 08005 Barcelona, Spain (Balbo and Medella)/Institució Milà i Fontanals, Spanish National Research Council (IMF-CSIC), C/Egipciaques 15, 08001 Barcelona, Spain (Balbo)/Barcelona Supercomputing Center (BSC), Nexus II Building, C/Jordi Girona 29, 08034 Barcelona, Spain (Rubio-Campillo)/ Institució Catalana de Recerca i Estudis Avançats (ICREA), 08010 Barcelona, Spain (Madella and Reyes-García). This paper was submitted $28 \mathrm{~V} \mathrm{14}$, accepted 02 XI 14, and electronically published 6 IV 15.

CA+ Online-Only Material: Supplements A and B

Understanding the patterns and processes underlying the heterogeneous distribution of traditional ecological knowledge (TEK) across communities of natural resource users is a growing research topic. However, social organization as a factor potentially shaping TEK intracultural distribution has received scant attention. Here, we analyze the role played by kinship groups - namely, patrilineal lineages and segmentsin shaping bodies of TEK among a group of seminomadic pastoralists in India. We use two quantitative approaches (score based and similarity based) to analyze variations in four TEK domains: soils, ethnoveterinary, breeds, and ethnobotany. We find that kinship groups share divergent bodies of knowledge, a finding that we interpret in light of the social organization of migration, in which kinship provides a privileged basis that structures migratory groups and, as such, favors the constitution of shared bodies of knowledge. We conclude by advocating for a better inclusion of the organizational features that structure the collective life of local communities in research aiming at understanding TEK dynamics.

(C) 2015 by The Wenner-Gren Foundation for Anthropological Research. All rights reserved. 0011-3204/2015/5603-0010\$10.00. DOI: 10.1086 1680438
Research shows that traditional ecological knowledge $(\mathrm{TEK})^{1}$ systems play an important role in natural resource management (Berkes, Colding, and Folke 2000) and that heterogeneity in actors and in the knowledge they hold is likely to increase the adaptive capacity of local communities by widening the options for action (Folke et al. 2005). Therefore, uncovering the processes explaining heterogeneous TEK distribution is a key research topic, especially in fast-changing contexts (Gunderson and Holling 2002).

Previous research addressing TEK intracultural variations has identified some patterns between peoples' TEK, their social roles, and the organizational features of their communities. First, knowledge distribution seems to be affected by individual characteristics, such as age (Begossi, Hanazaki, and Tamashiro 2002), gender (Camou-Guerrero et al. 2008), level of integration into the market economy (GomezBaggethun et al. 2010), formal education (Zarger 2002), and livelihood strategies (Pilgrim et al. 2008). Such factors proxy for an individual's social roles, so they-somehow-also capture the sociocultural context in which TEK production and transmission is embedded. Second, group pertinence also seems to shape intracultural distribution of TEK. Both informal (Reyes-García et al. 2013) and occupation-related (Crona 2006; Ghimire, McKey, and Aumeeruddy-Thomas 2004) groups involved in heterogeneous uses of natural resources hold divergent bodies of TEK.

Interestingly, although social context is implicitly encompassed in such analyses, most previous work does not consider social organization per se as a factor shaping TEK distribution. In this research, we analyze the role played by kinship, a cornerstone of social organization (Fox 1967), in shaping TEK distribution. Kin-based organization is of special interest as it partitions local communities into diverse subgroups maintaining complex relations. It also provides a preferential basis for interindividual interactions. Indeed, previous works have examined the role played by kin-based groups in TEK transmission processes. Cavalli-Sforza and Feldman (1981) formalized this idea with their model of vertical (parent-child) cultural transmission. Lozada, Ladio, and Weigandt (2006) and Ohmagari et al. (1997) demonstrated that TEK is mainly transmitted from parents to children, at least at a young age, while Boster (1986) showed that Aguaruna kin-related women display a higher degree of consensus regarding manioc identification. Yet these works focus on the household, neglecting higher levels of kin-related clustering (such as lineages or clans) as factors potentially

1. We define TEK in accordance with Berkes, Colding, and Folke (2000:1252) as "a cumulative body of knowledge, practice and belief, evolving by adaptive processes and handed down through generations by cultural transmission, about the relation of living beings (including humans) with one another and with their environment." 
shaping TEK variations. However, the critical role played by higher kinship levels in shaping agrobiodiversity (Labeyrie, Rono, and Leclerc 2014; Leclerc and Coppens d'Eeckenbrugge 2011) raises the question of whether such kinship levels might also play a role in explaining knowledge distribution.

We address the question using data from a nomadic pastoralist society. Within nomadic pastoralist societies, kinship is of specific relevance as an organizational principle. Despite many differences, the migrating collectives of pastoral societies in Asia and Africa almost always cluster kin-related men and their households. For instance, Barth (1961:35) stressed the importance of agnatic, matrilateral, and affinal bonds within migrating camps of Basseri nomads, to balance the divisive effect of disagreement resulting from daily decision making regarding herd management. In Africa, similar trends have been described among the Samburu herders (Spencer 2004 [1965]), whose settlements, although semipermanent, were mainly built on kinship relations; McCabe (2004:57) describes close features among the Turkana, stressing the importance of in-laws. These works also show the importance of kin-based networks for support between herders and for access to pastures, as access rights are often attached to kinbased groups (Barth 1961:55). Thus, as kin-based organization underlies most of nomadic life, it is also likely to affect TEK distribution within pastoralist communities. Our aim here is specifically to test this hypothesis.

\section{Case Study}

The Raika/Rabari community (hereafter, Rabari; around 600,000 people) is found mainly across the states of Rajasthan and Gujarat, India (Prévot 2007). Over the past decades, this pastoralist community has faced important internal and external changes, driven by intermingled factors ranging from the India/Pakistan partition to the Indian Green Revolution (Choksi and Dyer 1996). These changes have resulted in increasing difficulties to pursue a seminomadic pastoralist livelihood. Accordingly, the contemporary Rabari community of Gujarat shows varying degrees of sedentarization and occupational diversification. Camel keeping, traditionally the primary occupation of the Rabari, is scarcely continued (Bharwada and Mahajan 2010); in contrast, many Rabari are now

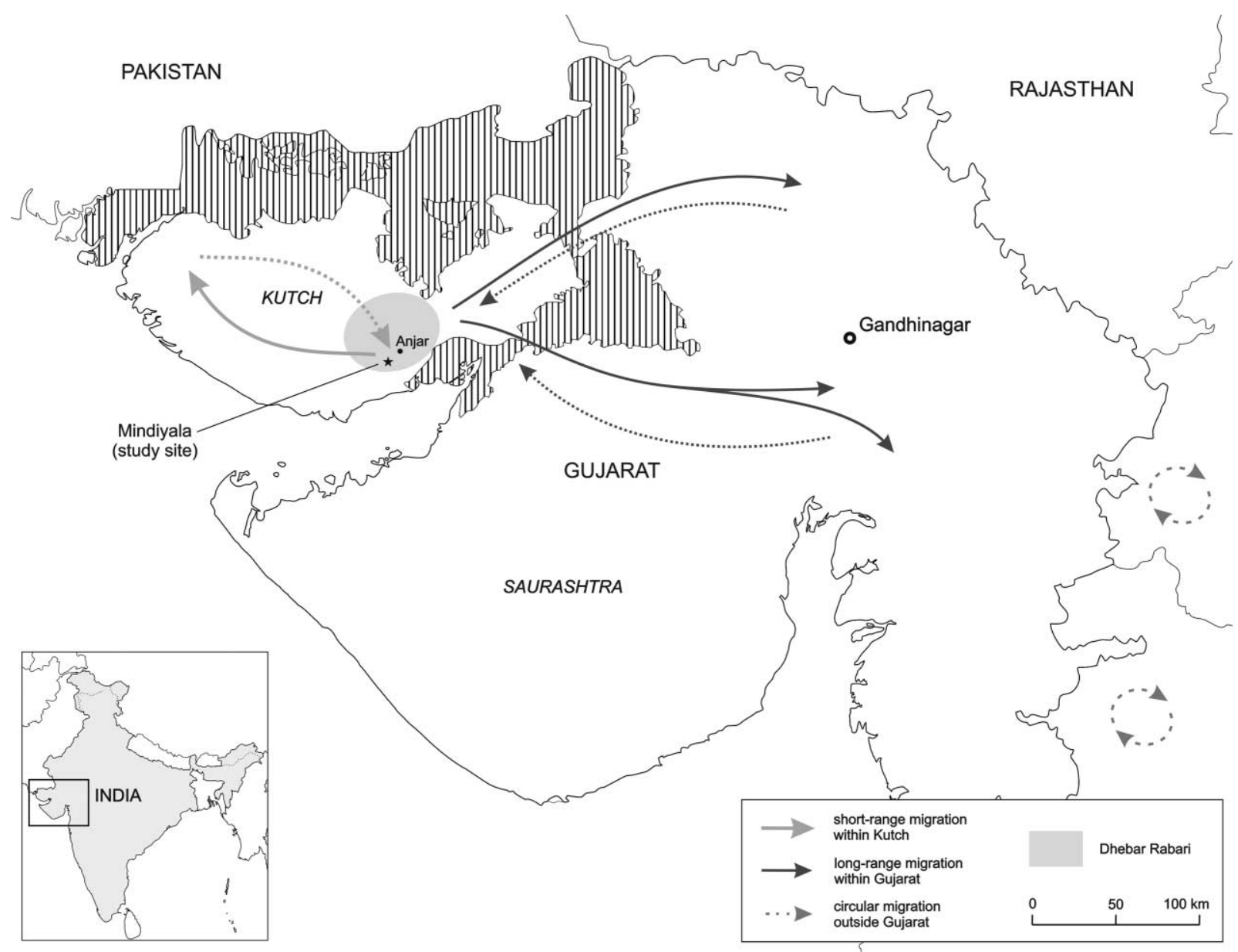

Figure 1. Map of the research area showing the main patterns of migration of Rabari pastoralists from the Anjar taluka. Source: Adapted from d-maps.com (visited June 4, 2013) and Gujarat state map, Government of Gujarat. A color version of this figure is available online. 
sedentary and engaged in diverse economic activities. Smalllivestock rearing is mainly carried on in Kutch and Saurashtra, involving seasonal migrations partly determined by the monsoon-driven climate. In Kutch, the seasonal moves follow three main patterns: small-range migration within Kutch, long-range migration between Kutch and Gujarat hinterlands, and circular migration within a delimited area outside Gujarat (fig. 1).

As in other nomadic societies (Mauss 1979), Rabari social organization varies according to migration stage (fig. 2). While migrating (from 1 to 12 months a year), Rabari social organization is based on two main units: the household, which includes the nuclear family plus some casual workers, and the migrating group (dang), which clusters a number of households under one leader (patel) and sometimes a council of elders (Prévot 2007; M. Salpeteur, personal observation). Men and women migrate together, sometimes with children; all households of a given dang camp together every evening. Large dangs ( $>10$ households) usually include households from different kin groups or villages, whereas small dangs are typically limited to the households of closely related men: a father and his sons, several brothers, and the like.

Besides this migration organization, the Rabari are socially organized in subcaste divisions and descent. Paragana are territorial community subdivisions associated with a specific area. Paragana differ from each other on some minor cultural traits and on migration routes. These groups are not based on kinship but tend to be endogamous. The second division concerns clans (shak or atak), exogamous patrilineal descent groups found across the different paragana and across the whole Rabari community (i.e., members of one clan are found in different regions). These clans are further divided into patrilineal lineages (vaas), which cluster from four to more than eight generations. Such lineages are named following the founder's name (e.g., Dhana-ni, for "Dhana's people"), and they experience ongoing segmentation, as after some generations a man can create his own lineage, which will grow besides the original one. As a result, lineage segments holding different names may originate from the same ascent. Here we follow classical kinship terminology (Fox 1967) and distinguish between the oldest lineage groups from which all current subgroups originate (hereafter, "lineages") and the small segments of lineage to which individuals refer nowadays (hereafter, "segments").

\section{Methods}

Data were collected in Gujarat from February 2012 to February 2013. After collection of background information, we selected the Anjar taluka, a subdivision of the Kutch dis-
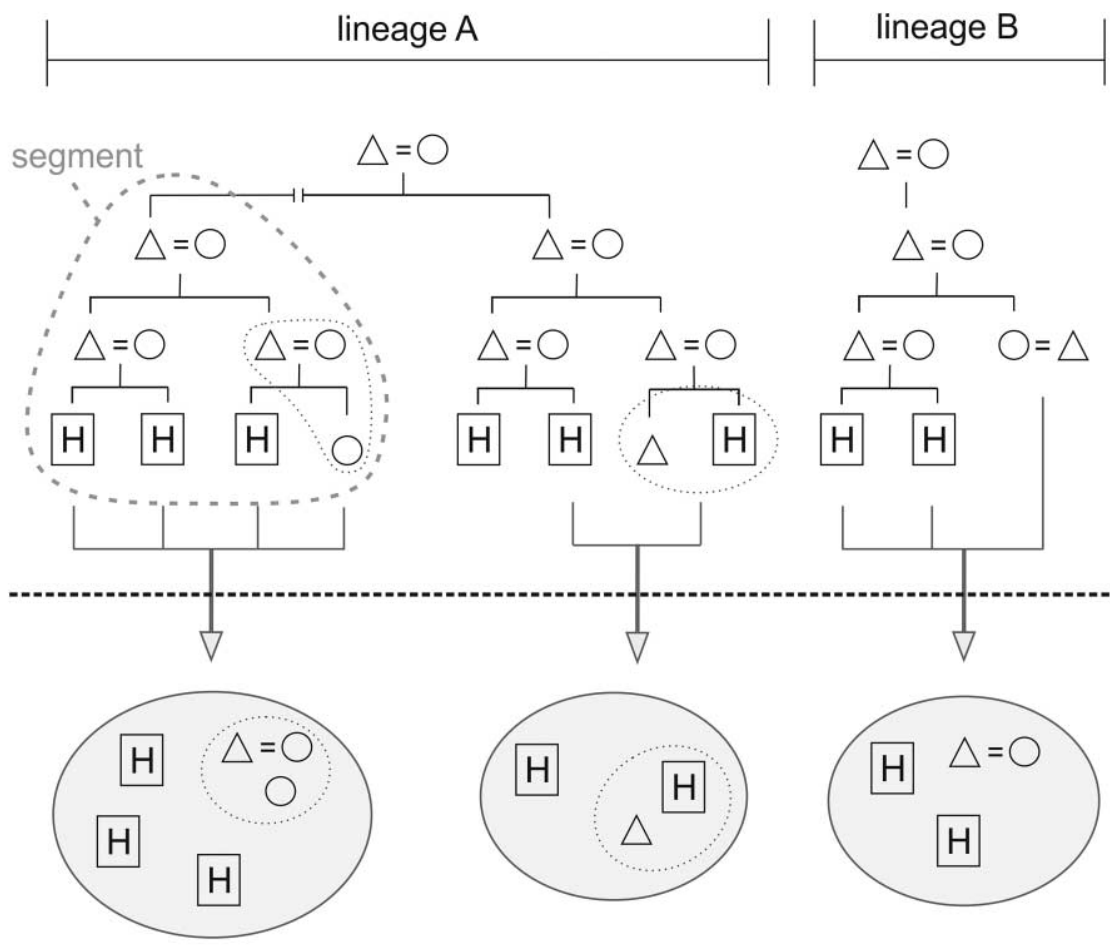

1

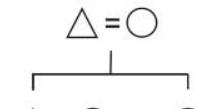

sedentary phase
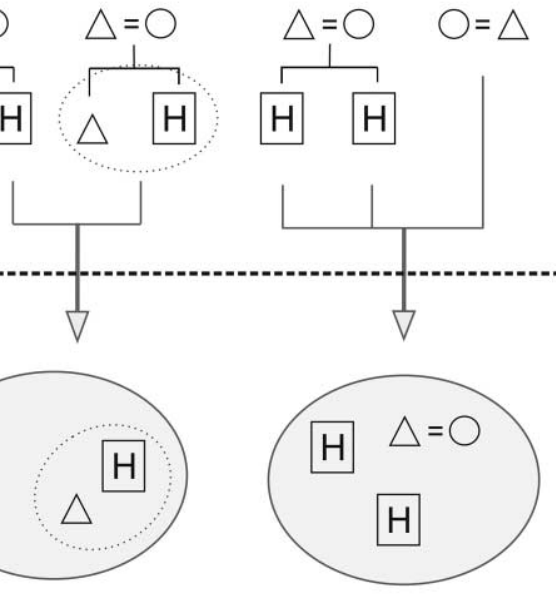

nomadic phase

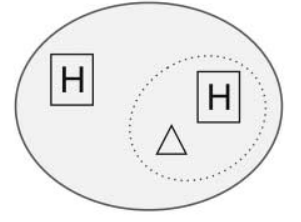

romactic phase

migration groups (dang)

$\mathrm{H}=$ household

Figure 2. Schema of the Rabari social organization during sedentary and nomadic phases. A color version of this figure is available online. 
trict, for in-depth analysis. For 8 months, we conducted semistructured interviews, focus groups, and participant observation with members of the Rabari community (Salpeteur et al., forthcoming). We finally focused on the village of Mindiyala, where we conducted a questionnaire survey. We visited compounds and asked people about their availability and willingness to participate. We used village census data to select a sample stratified across gender and lineage composition, and we adjusted the sample selection daily to achieve the desired quota. Our final sample included 164 individuals (83 women and 81 men) belonging to 21 segments clustered in four lineages (with women being included in husband's segments). Thus, although our sample represents only $6.6 \%$ of the total village population, it covers all its existing lineages and segments. Our questionnaire included three sections: (1) sociodemographic information and social group membership, (2) pastoralist experience, and (3) TEK. To ensure that our questions captured TEK variability, we pilot-tested the survey in a different village. As some studies stress that TEK distribution can vary between domains (Gomez-Baggethun et al. 2010), we included questions covering a range of shepherds' daily tasks, regarding four different domains:

1. Soil qualities (TEK_soils): Rabari pastoralists describe soils using qualitative terms based on an analogy with food tastes: mitho (sweet), kharo (salty), and moro (tasteless). These categories are not to be equated with the degree of salinity of soils, as most of the areas of Kutch identified as saline by soil scientists are categorized as moro by Rabari shepherds. Each soil category is associated with specific vegetation having a nutritional value for animals: mitho and kharo areas are seen as good pastures, whereas moro areas are seen as poor.

2. Ethnoveterinary (TEK_tado): Although the use of chemical drugs to cure animals is widespread today (Geerlings 2001), the traditional iron-rod cauterization (tado) is also regularly used (Singh et al. 2014). Tado consists of burning with iron tools the skin of the sick animal. The body part to be burnt and the design to be drawn (i.e., circle, cross) are disease specific (see $\mathrm{CA}+$ online supplement $\mathrm{A}$ and associated photos for more details on this healing method).

3. Breeds (TEK_breeds): Breed knowledge is an important aspect of herd management, as the choice of breeds affects herd quality. Breeds are chosen depending on the intended product (wool or meat) and pastoral activity (length and areas of migration).

4. Ethnobotany (TEK_botany): The use of plants with medicinal and veterinary properties is common among the Rabari (Geerlings 2001). We documented the curative properties of several plant species and selected a subset to be included in the questionnaire.

We selected 11 questions on soils, four on breeds, and nine on ethnobotany. The questions were either multiple choice or binary. To proxy tado knowledge, we asked informants to free-list all of the diseases they knew to be cured using tado and to describe the part of the body and the design to be burned (see CA+ online supplement B).
We analyzed data using two approaches. First, we built individual domain-specific TEK scores. Following ReyesGarcía et al. (2007), we used the cultural consensus analysis (Romney, Weller, and Batchelder 1986) procedure in Anthropac software (Borgatti 1996) to find the answer key (most common answer) to each question. Individual answers were then compared with the answer key (match $=1$ point, no match $=0$ points) and summed to generate a score. To allow comparability, scores were scaled linearly on a $0-100$ basis (individual's matched answers divided by the total number of answers, multiplied by 100). For TEK_tado, the score was calculated using the number of diseases and associated cures given by informants. Such scores were used to

Table 1. Descriptive statistics of utilized variables

\begin{tabular}{|c|c|}
\hline Variable & Value \\
\hline \multicolumn{2}{|l|}{ Individual characteristics: } \\
\hline Gender (\% of men) & 49.39 \\
\hline \multicolumn{2}{|l|}{ Age group: } \\
\hline Young $(0-20$ years $)$ & 8 \\
\hline Middle (21-40 years) & 69 \\
\hline Mature (41-60 years) & 50 \\
\hline Old (61 years or more) & 37 \\
\hline \multicolumn{2}{|l|}{ Schooling: } \\
\hline Did the individual go to school? & 22.75 \\
\hline \multicolumn{2}{|l|}{ Pastoralist experience: } \\
\hline \multicolumn{2}{|l|}{ Shepherd experience: } \\
\hline None (never been shepherd) & 24 \\
\hline Past (retired shepherd) & 109 \\
\hline Current (currently shepherd) & 31 \\
\hline \multicolumn{2}{|l|}{ Occupation change delay: ${ }^{\mathrm{a}}$} \\
\hline Short $(0-4$ years $)$ & 33 \\
\hline Mean (5-9 years) & 31 \\
\hline Long (10 years or more) & 45 \\
\hline \multicolumn{2}{|l|}{ Group leader: } \\
\hline $\begin{array}{l}\text { Was (or is) leader of a migration group } \\
\text { (yes/no, } \% \text { of yes) }\end{array}$ & 23.95 \\
\hline \multicolumn{2}{|l|}{ Family involvement in sheep keeping: } \\
\hline \multicolumn{2}{|c|}{ Ascendant involvement (father and grandfather): } \\
\hline Low (one or both were not shepherds) & 29 \\
\hline High (both were shepherds) & 135 \\
\hline \multicolumn{2}{|l|}{ Close relative involvement: } \\
\hline Low ( $0-4$ persons $)$ & 128 \\
\hline High (5 persons or more) & 36 \\
\hline \multicolumn{2}{|l|}{ TEK indexes (mean $\pm 95 \% \mathrm{CI})$ : } \\
\hline TEK_soils & $65.11 \pm 3.84$ \\
\hline TEK_tado & $36.71 \pm 4.13$ \\
\hline TEK_breeds & $39.48 \pm 4.2$ \\
\hline TEK_botany & $53.31 \pm 4.6$ \\
\hline
\end{tabular}

Note. Data are number of participants, unless otherwise indicated. Traditional ecological knowledge (TEK) indexes are as follows: TEK_soils = sum of the scores obtained for 11 questions about soil types (normalized to 0-100); TEK_tado $=$ number of items cited as diseases known to be cured through tado (normalized to 0-100); TEK_breeds = sum of the scores obtained for four questions about origin of breeds of sheep (normalized to 0-100); and TEK_botany = sum of the scores obtained for nine questions about uses of plants (normalized to $0-100$ ). CI $=$ confidence interval.

a Applied only to retired shepherds $(n=109)$. 


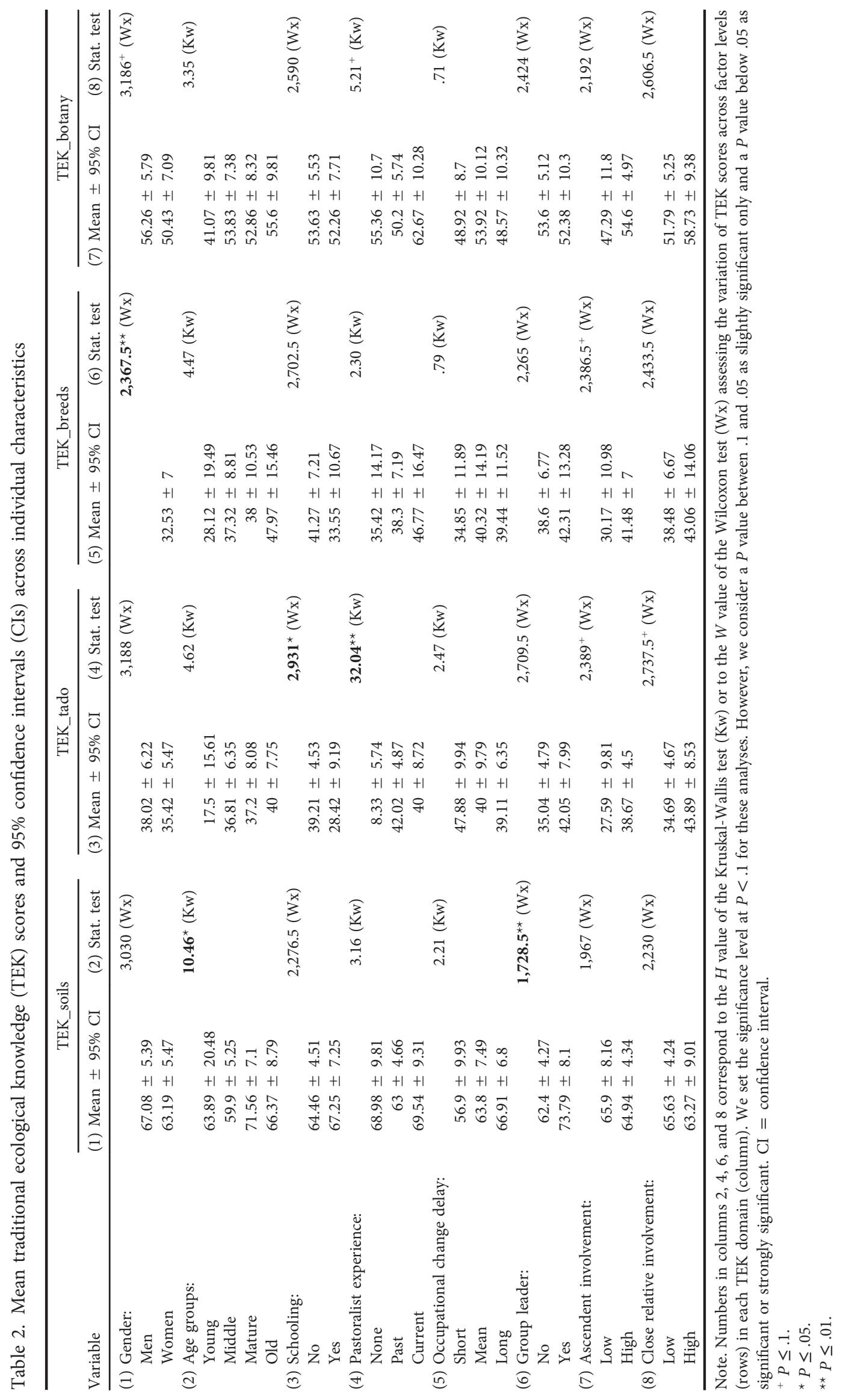


analyze TEK variations in relation to (1) sociodemographic variables and (2) lineage and segment membership. To assess the statistical significance of observed variations, we used the Kruskal-Wallis test for variables with more than two levels (e.g., age groups) and the Wilcoxon rank sum test for twolevel variables (e.g., gender). Such nonparametric tests are relevant when comparing subsamples that have heterogeneous population size, as in our case (table 1).

With this approach, answers differing from the answer key are globally recoded as false regardless of the differences and similarities between individual answers. Therefore, our second approach explicitly takes into consideration the similarity of answers between individuals. Drawing on Labeyrie, Rono, and Leclerc (2014), we used the Jaccard similarity index to measure distance between individual answers in each domain. We then computed a between-class correspondence analysis (BCA) on the distance matrices, comparing individual answers across the selected levels of social organization. $\mathrm{BCA}$ is a multivariate ordination analysis that enables testing of whether similarity is higher within or between groups, computing principal components in a way that maximizes variance between groups (Chessel, Dufour, and Thioulouse 2004; Labeyrie, Rono, and Leclerc 2014). A first application of BCA to the study of TEK variations can be found in Menendez-Baceta et al. (2015). We conducted Monte Carlo tests, running 9,999 permutations of individual answers, to test the significance of the BCA measures, which were com- puted at each level of social organization for each knowledge domain. Last, to measure the weight of each variable (individual characteristics and kinship groups) in explaining the observed variations, we ran permutational multivariate analysis of variance (PERMANOVA) on the distance matrices. This analysis functions as a multiple linear model, evaluating the weight of each variable in explaining the observed variations (Oksanen et al. 2014). We used R software for analyses (R Development Core Team 2011).

We are aware that our strategy is subject to at least two important caveats: self-selection bias and measurement error. First, as about one-third of the Mindiyala population was migrating at the time of the survey, our sample might underrepresent migrating households. We tried to minimize this bias by including migratory camps in the survey, but we cannot assess the size of the bias. Second, the use of questionnaires to proxy TEK does not provide a full picture of the actual knowledge individuals hold, thus potentially generating measurement error. We based our questionnaires on information collected during 8 months of fieldwork, but measurement errors likely remain.

\section{Results}

\section{Individual-Level TEK Variations}

We found that individual-level characteristics are associated with TEK intracultural variations (table 2). As these do not
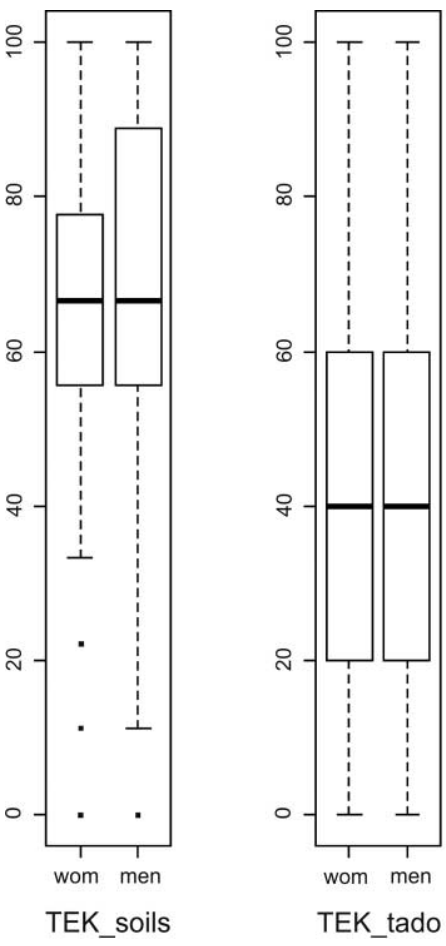

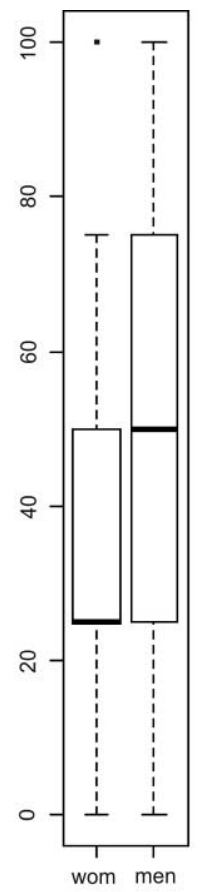

TEK_breeds

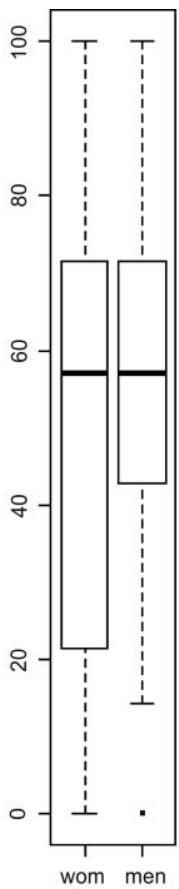

TEK_botanical

Figure 3. Score distribution in each traditional ecological knowledge (TEK) index between the two gender groups (see table 2, col. 1). 


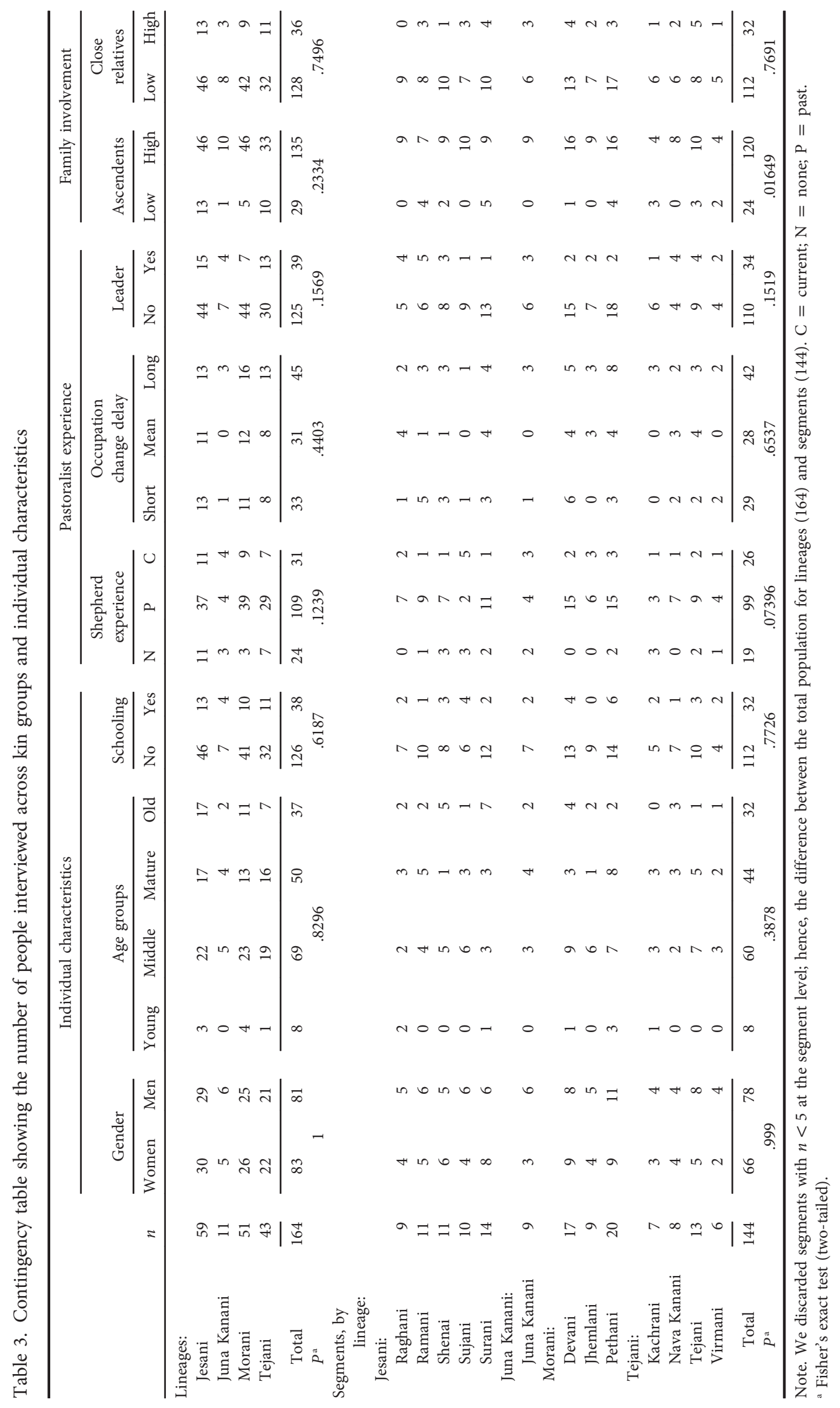




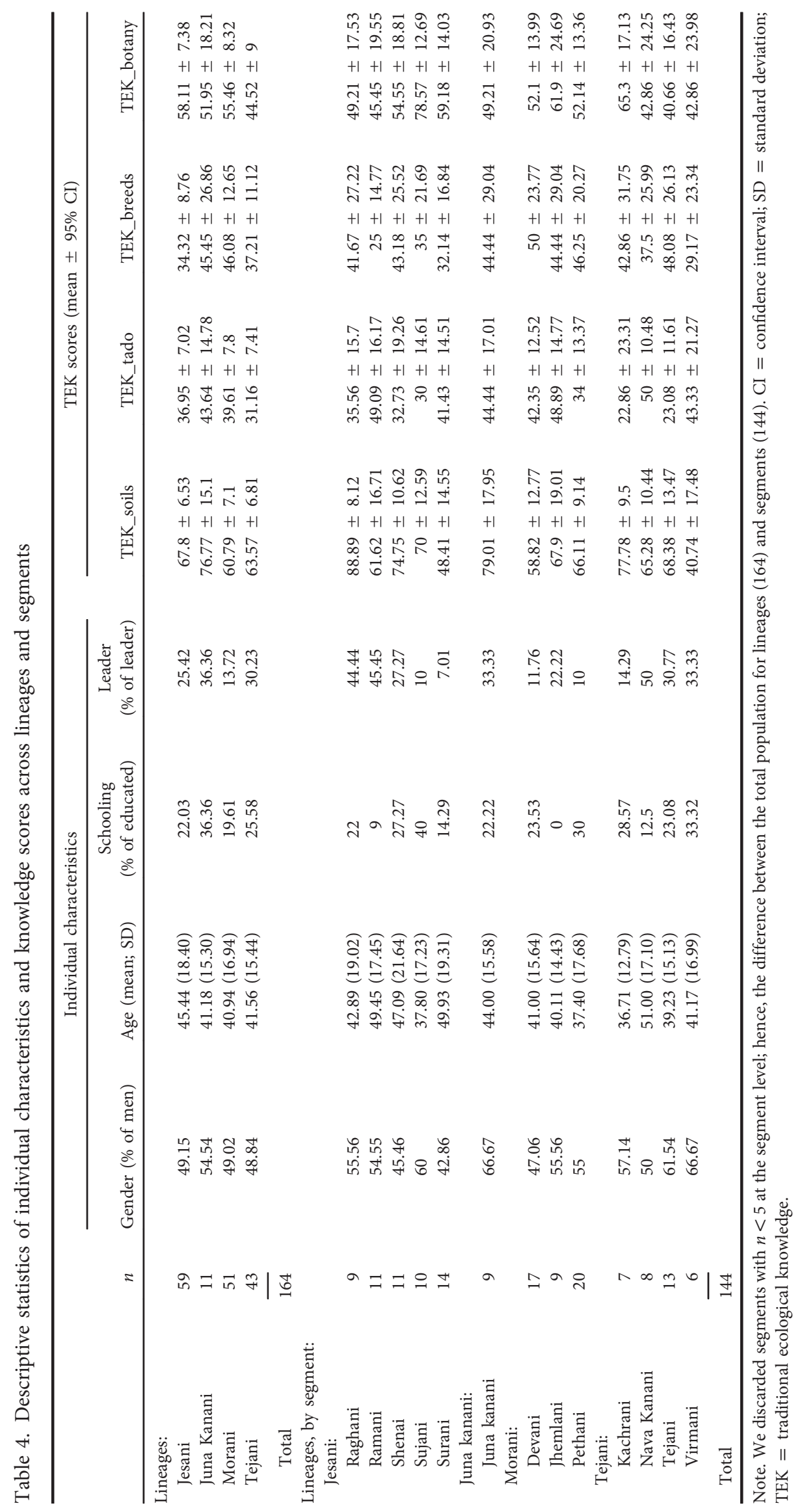


Table 5. Kruskal-Wallis $H$ values obtained when testing the variability of knowledge scores between segments and lineages

\begin{tabular}{|c|c|c|c|c|c|c|}
\hline & \multicolumn{3}{|c|}{ Segment } & \multicolumn{3}{|c|}{ Lineage } \\
\hline & (1) Whole population & (2) Men & (3) Women & (4) Whole population & (5) Men & (6) Women \\
\hline TEK_soils & $29.522^{\star *}$ & 10.885 & 3.037 & 5.769 & 1.07 & $7.106^{*}$ \\
\hline TEK_tado & 15.844 & 10.528 & 5.954 & 2.777 & .676 & 3.267 \\
\hline TEK_breeds & 13.289 & 10.959 & $10.52^{+}$ & $7.605^{+}$ & $8.047^{\star}$ & .695 \\
\hline TEK_botany & 16.146 & 9.006 & 5.557 & 5.486 & .469 & $7.212^{\star}$ \\
\hline
\end{tabular}

Note. TEK = traditional ecological knowledge.

$+P \leq .1$.

${ }^{*} P \leq .05$.

** $P \leq .01$.

constitute our main focus, we here describe the main tendencies found before presenting results related to kinship groups. Gender significantly affected the distribution of scores in the TEK_breeds domain $(P<.001)$, with women displaying lower scores than men (cols. 5-6, row 1; fig. 3). TEK_soils scores also varied significantly across age categories (col. 2, row 2), and formal schooling was associated with lower TEK tado scores (col. 4, row 3). These results could be mediated by the strong association between schooling and occupation $\left(\chi^{2}, P<.0001\right)$, as younger individuals were both more educated and less involved in shepherd activity.

Pastoralist experience (row 4) significantly affected TEK_ tado scores $(P<.01)$ and slightly affected TEK_botany scores $(P<.1)$. Differences were especially important for individuals without shepherd experience compared with individuals in the two other categories (row 4, cols. 4-8). Interestingly, the amount of time elapsed since the abandonment of smalllivestock keeping does not seem to affect TEK (row 5). Leaders of migration groups had significantly higher TEK_soils scores than nonleaders (col. 2, row 6).

A final result is that the involvement of close relatives in sheep keeping had a slight influence on individual knowledge: higher involvement of ascendants (father and grandfather) was associated with higher scores for TEK_breeds $(P<.1)$, and higher involvement of both ascendants and close rela- tives was associated with slightly significant differences for TEK_tado $(P<.1$; rows 7-8, cols. 3-6).

\section{Group-Level TEK Variations}

Table 3 is a contingency table crossing kin groups and individual characteristics, table 4 displays knowledge scores across kin groups, and table 5 shows the results of comparing knowledge scores across lineages and segments. As gender was shown to affect TEK distribution, we ran separate analyses for subsamples of men (Table 5, cols. 2, 5) and women (cols. 3, 6). For the full sample, we found significant differences between segments regarding TEK_soils (col. 1; $P<$ .01 ) and slight differences for the women's subsample regarding TEK_breeds $(P<.1)$. We also found variations in the same domains across lineages: for the women's subsample in TEK_soils $(P<.05)$ and for both the full sample $(P<.1)$ and the men's subsample $(P<.05)$ in TEK_breeds (cols. $4-6)$.

The BCA provides different insights on these variations (table 6). For some domains, results match our previous analyses: TEK_soils varied between segments for the whole population $(P<.001)$, and TEK_breeds varied between lineages when considering men $(P<.05$; letters $\mathrm{A}$, D in table 6$)$. BCA also revealed other variations: in TEK_botany significant variations were observed between men's segments $(P<$

Table 6. Simulated $P$ values obtained from the between-class analysis when testing the variability of individual answers between groups, for segments and lineages

\begin{tabular}{lcccccccc}
\hline & \multicolumn{3}{c}{ Segment } & & \multicolumn{3}{c}{ Lineage } \\
\cline { 2 - 3 } & $(1)$ Whole population & $(2)$ Men & (3) Women & & (4) Whole population & (5) Men & (6) Women \\
\hline TEK_soils & $<.001^{* *}(\mathrm{~A})$ & .1486 & .653 & & .329 & .1436 & .322 \\
TEK_tado & .1775 & $.9774^{*}(\mathrm{~B})$ & .1027 & & $.0567^{+}$ & .2773 & $.0266^{*}(\mathrm{C})$ \\
TEK_breeds & .37 & .2684 & .4355 & & .144 & $.0135^{*}$ (D) & .5756 \\
TEK_botany & $.0553^{+}$ & $.036^{*}(\mathrm{E})$ & .3663 & & .181 & .2232 & .1917 \\
\hline
\end{tabular}

Note. TEK = traditional ecological knowledge.

$+P \leq .1$.

${ }^{*} P \leq .05$.

${ }^{* *} P \leq .01$. 


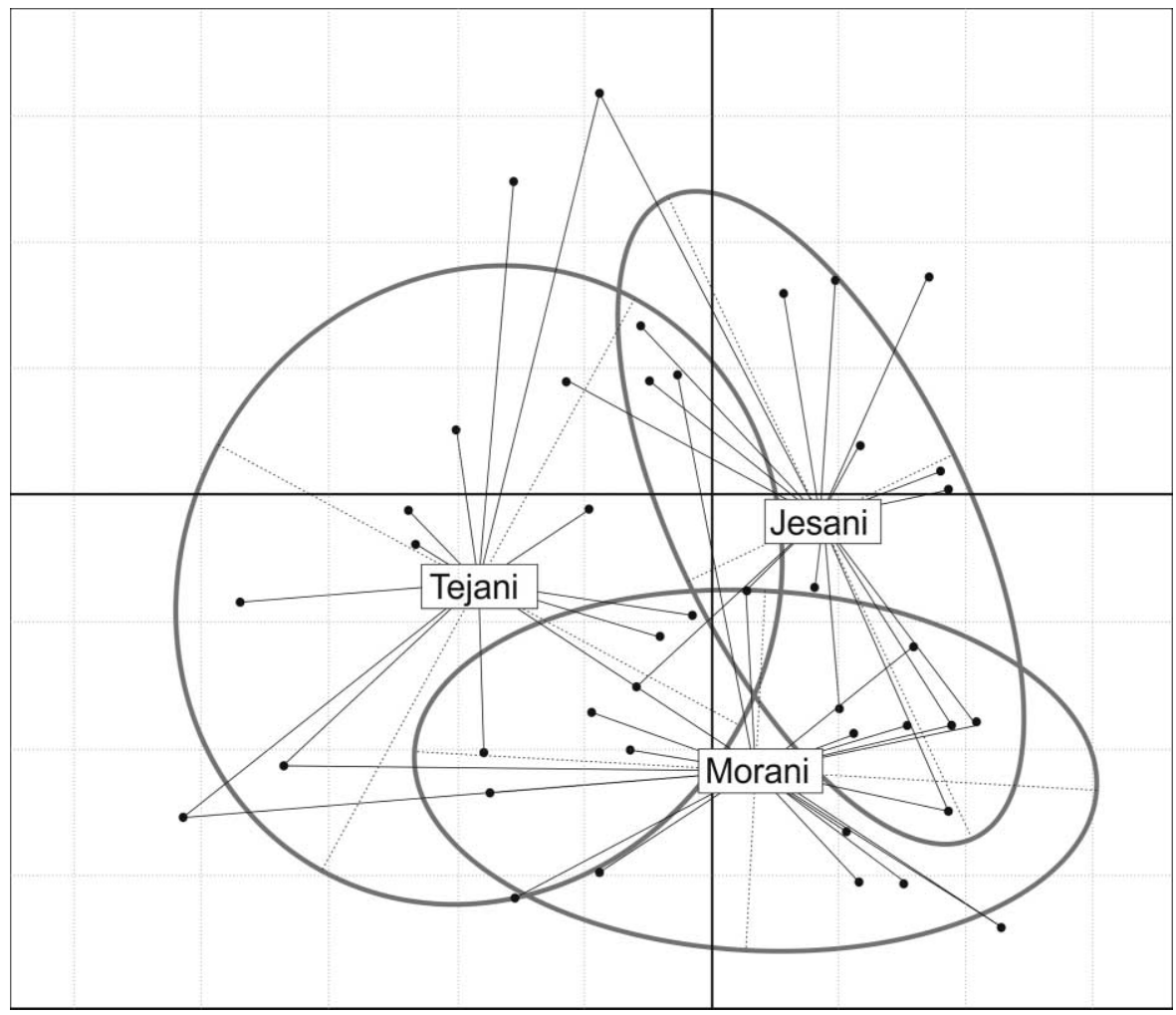

Figure 4. Projection in a two-dimensional space of the variability in individual answers (women, TEK_tado domain) between lineage groups (table 5, col. 6, row 2). Points represent individuals and ellipses represent lineages, with gravity centers. The two main components (eigenvalues) of the between-class correspondence analysis account for $60.1 \%$ and $39 \%$ of the total inertia, or intergroup variability.

.05; E in table 6), and slightly significant variations were observed between whole-population segments $(P<.1)$. Regarding TEK_tado, significant variations were observed between men's segments $(P<.05 ; \mathrm{B})$ and, at the lineage level, for women $(P<.05 ; \mathrm{C})$ and for the whole population $(P<.1$; figs. 4, 5).

Finally, the PERMANOVA, which clustered all explaining variables (individual characteristics and kinship groups) in multiple linear models, showed that in the five cases where BCA revealed highly significant values (A-E in table 6), the kinship groups explained a significant part of the observed variations, besides the other factors (table 7 ). For the analyses focusing on the segment level $(A, D, E)$, the segment variable appears highly significant $(P<.01$ or $P<.05)$, explaining $11 \%$ of the variation for TEK_soils and TEK_tado (A, B) and $15 \%$ of the variation for TEK_botany (E). The other significant variables explained lower percentages of the variation: the age and function of group leader accounted for $2.8 \%$ and $0.9 \%$, respectively, of the variation for TEK_soils (A); schooling and close relative involvement accounted for $4.7 \%$ and $4.8 \%$, respectively, of the variation for TEK_tado (B); and schooling, shepherd experience, and delay of occupation change explained $1.9 \%-4.3 \%$ of the variation for TEK_botany (E). Regarding analyses including lineage level
(C, D), the lineage variable accounted for a lower percentage of variation $(4.7 \%$ and $4.3 \%$, respectively), while other significant variables also appeared: schooling and delay of occupation change for TEK_tado between women (C; 3.3\% and $6.4 \%$, respectively) and age and schooling for TEK_breeds (D; $5.2 \%$ and $2.5 \%$, respectively). These results are sensitive to the distribution of variance within each group, which in our case is not strictly homogeneous, so some of these values may result from this condition.

Overall, our results provide a detailed picture of TEK variations across kin groups. Both approaches (score based and similarity based) demonstrate a strong and consistent variation of TEK_soils and TEK_breeds across kin groups. Different patterns of variations are observed for TEK_botany: the score-based approach suggests that knowledge varies across lineages for the women's subsample, a finding not confirmed by the BCA. The inverse situation is observed at the segment level, for the whole population and for the men's subsample (table 6, cols. 1-2). Last, in the case of TEK_tado, although the score-based approach does not suggest the existence of significant variations across kinship groups, the similarity-based approach suggests that disease names cited by interviewees were significantly different from one kinship group to another, with a higher homogeneity within groups. 


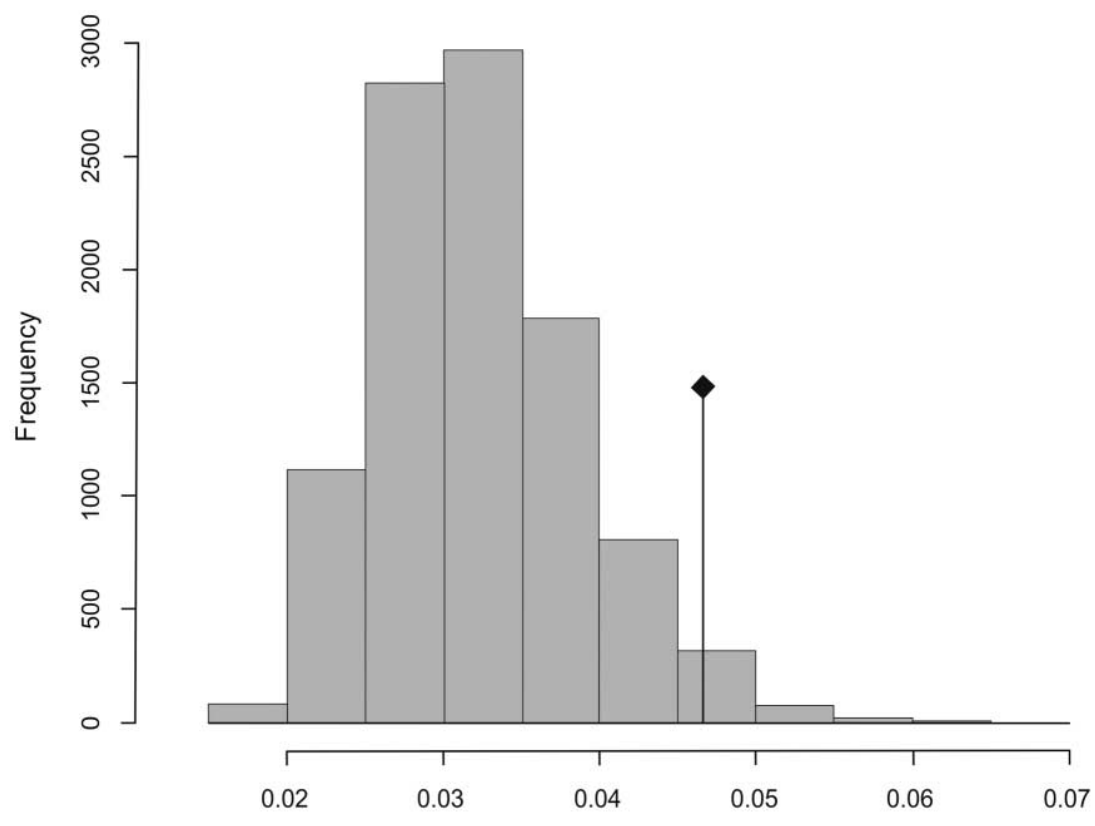

Figure 5. Monte Carlo simulation of the $P$ value for the between-class analysis, applied to lineages, women's population, and TEK_tado index (simulated $P$ value $=.0266$ ).

The PERMANOVA confirmed these results, showing that kin-related variables explain in a strongly significant way the overall observed variations, accounting for $4.3 \%-15 \%$ of these variations.

\section{Discussion}

Results from our work confirm that TEK varies across individuals and groups, although this variation sometimes follows an unexpected direction. For example, we did not find significant variations between men's and women's tado, soils, or ethnobotanical knowledge, a finding that seemingly contradicts previous work on the gendered distribution of TEK (Camou-Guerrero et al. 2008). Our finding, however, makes sense in the ethnographic setting, where extensive ethnoveterinary knowledge has been attested among Rabari women (Geerlings 2001). Other patterns of variation depend on the domain of knowledge. The strong relationship between a person's occupation and tado and breed knowledge suggests that the daily practices of animal keeping are key in the development and maintenance of these bodies of knowledge. Our findings imply that, once acquired, this knowledge remains with the individual even after the abandonment of the activity, although it might not be transmitted to individuals who do not engage in the occupation. In such a context, current strong occupational shifts observed might be leading to the loss of these specific bodies of TEK. Interestingly, the two other domains examined, soils and ethnobotany, do not vary much with pastoralist experience, probably because they are not specific to such practice. Indeed, our ethnobotanical questions referred to locally abundant and commonly used plant species, whereas soil-quality knowledge might also be acquired while performing other activities, such as farming. The higher soil knowledge among leaders of migration groups can relate to one of their duties while on the move: they are responsible for scouting potential grazing areas and choosing camp sites, for which they need to assess the potential of a wide range of areas.

Our main finding relates to kin-level variations in TEK. Results provided by the two analytical approaches show consistent patterns of variation across the considered levels of social organization, with a higher homogeneity of knowledge within groups and significant differences between groups. The organizational locus at which these patterns are observed vary from one TEK domain to another, but the main observation remains: the considered kinship groups seem to actually shape TEK distribution.

Previous research evidences that the coexistence of groups involved in distinguished uses of natural resources explains the coexistence of diverging bodies of TEK (Crona 2006; Ghimire, McKey, and Aumeeruddy-Thomas 2004). In our case, such heterogeneous uses of resources are not observed: most of the population is - or was - involved in similar sheepkeeping practices. This makes our finding puzzling. The ethnography of migration here offers a potential explanation. As mentioned, the dang clusters households for a period spanning from few months to a full year. Thus, it constitutes a privileged place for collective life. Households camp in the open close to each other, and exchanges, discussions, and mutual help are common. Camp sites, pastures, daily herd 
Table 7. Results of the permutational multivariate analysis of variance used to discriminate the weight of each variable (individual characteristics and kinship groups) in explaining the observed variations and similarities in traditional ecological knowledge (TEK) domains

\begin{tabular}{|c|c|c|c|c|c|}
\hline \multirow[b]{2}{*}{ Dependent variable } & \multicolumn{5}{|c|}{$R^{2}$ value with significance level } \\
\hline & $\begin{array}{c}\text { TEK_soils, } \\
\text { segment level, } \\
\text { whole population } \\
\text { (A) }\end{array}$ & $\begin{array}{l}\text { TEK_tado, } \\
\text { segment level, } \\
\text { men's subsample } \\
\text { (B) }\end{array}$ & $\begin{array}{c}\text { TEK_tado, } \\
\text { lineage level, } \\
\text { women's subsample } \\
\text { (C) }\end{array}$ & $\begin{array}{l}\text { TEK_breeds, } \\
\text { lineage level, } \\
\text { men's subsample } \\
\text { (D) }\end{array}$ & $\begin{array}{c}\text { TEK_botany, } \\
\text { segment level, } \\
\text { men's subsample } \\
\text { (E) }\end{array}$ \\
\hline Lineages & $\ldots$ & $\ldots$ & $.04667^{*}$ & $.04308^{*}$ & $\ldots$ \\
\hline Segments & $.10978^{\star *}$ & $.11442^{*}$ & $\ldots$ & $\ldots$ & $.15169^{* *}$ \\
\hline Gender & $\ldots$ & DV & DV & DV & DV \\
\hline Age & $.02807^{*}$ & $\ldots$ & $\ldots$ & $.05258^{+}$ & $\ldots$ \\
\hline Schooling & $\ldots$ & $.04660^{+}$ & $.03322^{\star *}$ & $.02538^{\star}$ & $.01875^{+}$ \\
\hline Shepherd experience & $\ldots$ & $\ldots$ & $\ldots$ & $\ldots$ & $.04343^{\star *}$ \\
\hline Occupation change delay & $\ldots$ & $\ldots$ & $.06358^{\star}$ & $\ldots$ & $.03679^{*}$ \\
\hline Group leader & $.00954^{+}$ & $\ldots$ & $\ldots$ & $\ldots$ & $\ldots$ \\
\hline Ascendant involvement & $\ldots$ & $\ldots$ & $\ldots$ & $\ldots$ & $\ldots$ \\
\hline Close relative involvement & $\ldots$ & $.04796^{+}$ & $\ldots$ & $\ldots$ & $\ldots$ \\
\hline
\end{tabular}

Note. Each column corresponds to a separate analysis, conducted to check each significant between-class correspondence analysis result (table 6 , letters A-E). Only significant results are included in this table. DV = discarded variable.

${ }^{+} P \leq .1$.

${ }^{*} P \leq .05$.

${ }^{* *} P \leq .01$.

care, and management are common topics of discussions. As dangs are mainly formed by kin, the bodies of knowledge set during the migration process, be it experiential or socially transmitted knowledge, are mainly shared across kin-related individuals. The migration groups are stable through years and rarely split. Thus, through these long-lasting relationships bodies of knowledge are likely to be transmitted from one generation to the next following a patrilineal descent. Our results suggest that this process leads to the emergence of diverging bodies of knowledge between descent groups (lineages and segments of lineages). Thus, across an apparently homogeneous community in which most individuals are involved in similar uses of natural resources, patterned variations of TEK related not to individual-level characteristics but to social organization might emerge.

\section{Conclusion}

A first remark relates to the specific social organization of seminomadic livelihoods: the pertinent level to be taken into account when assessing local TEK variations seems to be the migration group. This shows the interest of a specific focus on the social organization of migration when studying TEK in the context of seminomadic communities. But our most important conclusion relates to kinship, which seems to indirectly help shape TEK distribution among the Rabari pastoral communities of Gujarat. It does so by providing the underlying social structure that shapes migration groups, which in turn constructs common experiences and bodies of TEK. While the importance of the social structure embedding individuals' actions has been widely acknowledged (Granovetter 1985), it has received scant attention in TEK distribution research. Kinship constitutes a strong basis for social life, directly shaping primary groups such as nuclear families but also framing interindividual relations and collective actions in a more indirect way and at a wider level, as illustrated here. In future research, better inclusion of these organizational features in sampling strategies would improve the understanding of intracultural variations in TEK.

\section{Acknowledgments}

The research was funded by the former Spanish Ministry for Science and Innovation through the CONSOLIDER SimulPast project ("Simulating the Past to Understand Human Behaviour," CSD2010-00034). We thank all inhabitants of Mindiyala and Kutch who helped us, the Marag nongovernmental organization, V. Labeyrie for statistics implementation, and the reviewers for their helpful comments on the manuscript.

\section{References Cited}

Barth, Fredrik. 1961. Nomads of South Persia: the Basseri tribe of the Khamseh Confederacy. Oslo, Norway: Oslo University Press.

Begossi, Alpina, Natalia Hanazaki, and Jorge Y. Tamashiro. 2002. Medicinal plants in the Atlantic forest (Brazil): knowledge, use, and conservation. Human Ecology 30(3):281-299.

Berkes, Fikret, Johan Colding, and Carl Folke. 2000. Rediscovery of traditional ecological knowledge as adaptive management. Ecological Applications 10(5):1251-1262.

Bharwada, C., and V. Mahajan. 2010. Mangrove, markets and migration: camel pastoralists and conservation in the Gulf of Kutch, Gujarat. In Case studies of livestock environment interface experiences: LEAD Advocacy Network Project, Gujarat State. Pp. 29-53. Ahmedabad, India: Centre for Environment Education.

Borgatti, Stephen P. 1996. ANTHROPAC 4.0 methods guide. Natick, MA: Analytic Technologies. 
Boster, James S. 1986. Exchange of varieties and information between Aguaruna manioc cultivators. American Anthropologist 88(2):428-436.

Camou-Guerrero, Andres, Victoria Reyes-García, Miguel Martinez-Ramos, and Alejandro Casas. 2008. Knowledge and use value of plant species in a Raramuri community: a gender perspective for conservation. Human Ecology 36(2):259-272.

Cavalli-Sforza, L., and M. Feldman. 1981. Cultural transmission and evolution: a quantitative approach. Princeton, NJ: Princeton University Press.

Chessel, D., A. Dufour, and J. Thioulouse. 2004. The ade4 package I: onetable methods. R News 4:5-10.

Choksi, A., and C. Dyer. 1996. Pastoralism in a changing world: patterns of adaptation among the Rabaris of Kutch, Gujarat. Drylands Programme Issues Paper 69. London: International Institute of Environment and Development.

Crona, B. Irene. 2006. Supporting and enhancing development of heterogeneous ecological knowledge among resource users in a Kenyan seascape. Ecology and Society 11(1):32.

Folke, Carl, Thomas Hahn, Per Olsson, and Jon Norberg. 2005. Adaptive governance of social-ecological systems. Annual Review of Environment and Resources 30(1):441-473.

Fox, Robin. 1967. Kinship and marriage: an anthropological perspective. Cambridge: Cambridge University Press.

Geerlings, Ellen. 2001. Sheep husbandry and ethnoveterinary knowledge of Raika sheep pastoralists in Rajasthan, India. MSc thesis, Wageningen University. Accessed February 25, 2013. http://www.pastoralpeoples.org/docs /egfull.pdf.

Ghimire, Suresh Kumar, Doyle McKey, and Yildiz Aumeeruddy-Thomas. 2004. Heterogeneity in ethnoecological knowledge and management of medicinal plants in the Himalayas of Nepal: implications for conservation. Ecology and Society 9(3):6.

Gomez-Baggethun, Erik, Sara Mingorria, Victoria Reyes-García, Laura Calvet, and Carlos Montes. 2010. Traditional ecological knowledge trends in the transition to a market economy: empirical study in the Donana Natural Areas. Conservation Biology 24(3):721-729.

Granovetter, Mark. 1985. Economic action and social structure: the problem of embeddedness. American Journal of Sociology 91(3):481-510.

Gunderson, Lance H., and C. S. Holling. 2002. Panarchy: understanding transformations in human and natural systems. Washington, DC: Island.

Labeyrie, Vanesse, Bernard Rono, and Christian Leclerc. 2014. How social organization shapes crop diversity: an ecological anthropology approach among Tharaka farmers of Mount Kenya. Agriculture and Human Values 31(1):97-107.

Leclerc, Christian, and Geo Coppens d'Eeckenbrugge. 2011. Social organization of crop genetic diversity: the $\mathrm{G} \times \mathrm{E} \times \mathrm{S}$ interaction model. Diversity $4(1): 1-32$.

Lozada, Mariana, Ana Ladio, and Mariana Weigandt. 2006. Cultural transmission of ethnobotanical knowledge in a rural community of northwestern Patagonia, Argentina. Economic Botany 60(4):374-385.
Mauss, Marcel. 1979. Seasonal variations of the Eskimo: a study in social morphology. James J. Fox, trans. London: Routledge.

McCabe, J. Terrence. 2004. Cattle bring us to our enemies. Ann Arbor: University of Michigan Press.

Menendez-Baceta, Gorka, Laura Aceituno-Mata, Victoria Reyes-García, Javier Tardío, Matthieu Salpeteur, and Manuel Pardo-de-Santayana. 2015. The importance of cultural factors in the distribution of medicinal plant knowledge: a case study in four Basque regions. Journal of Ethnopharmacology 161:116127. doi:10.1016/j.jep.2014.12.007.

Ohmagari, Kayo, and Fikret Berkes. 1997. Transmission of indigenous knowledge and bush skills among the Western James Bay Cree women of subarctic Canada. Human Ecology 25(2):197-222.

Oksanen, Jari, F. Blanchet, Roeland Kindt, Pierre Legendre, P. R. Minchin, Bob O'Hara, Gavin L. Simpson, et al. 2014. The vegan package version 2.010: community ecology package. Accessed October 22, 2014. http://cran.r -project.org/package $=$ vegan.

Pilgrim, S. E., L. C. Cullen, D. J. Smith, and J. Pretty. 2008. Ecological knowledge is lost in wealthier communities and countries. Environmental Science and Technology 42(4):1004-1009.

Prévot, Sandrine. 2007. Les nomades d'aujourd'hui: ethnologie des Éleveurs Raika en Inde. Montreuil, France: Aux lieux d'être.

R Development Core Team. 2011. R: a language and environment for statistical computing. Vienna, Austria: R Foundation for Statistical Computing. Accessed May 21, 2013. http://www.R-project.org/.

Reyes-García, Victoria, Neus Marti, Thomas McDade, Susan Tanner, and Vincent Vadez. 2007. Concepts and methods in studies measuring individual ethnobotanical knowledge. Journal of Ethnobiology 27(2):182-203.

Reyes-García, Victoria, Jose Luis Molina, Laura Calvet-Mir, Laura AceitunoMata, Juan J. Lastra, Ricardo Ontillera, Montse Parada, et al. 2013. “Tertius Gaudens”: germplasm exchange networks and agroecological knowledge among home gardeners in the Iberian peninsula. Journal of Ethnobiology and Ethnomedicine 9:53-63.

Romney, A. K., Susan C. Weller, and William H. Batchelder. 1986. Culture as consensus: a theory of culture and informant accuracy. American Anthropologist 88(2):313-338.

Salpeteur, Matthieu, Marco Madella, Victoria Reyes-García, and Hanoz Patel. Forthcoming. Adaptation, access to resources and mobility: from contemporary pastoral systems to ancient societies. Nomadic Peoples.

Singh, Dheeraj, Subhash Kachhawaha, M. K. Choudhary, M. L. Meena, and P. K. Tomar. 2014. Ethnoveterinary knowledge of Raikas of Marwar for nomadic pastoralism. Indian Journal of Traditional Knowledge 13(1):123131.

Spencer, Paul. 2004 (1965). The Samburu. London: Routledge.

Zarger, R. 2002. Acquisition and transmission of subsistence knowledge by Q'eqchi' Maya in Belize. In Ethnobiology and biocultural diversity. J. Stepp, F. Wyndhamand, and R. Zarger, eds. Pp. 593-603. Athens: University of Georgia Press. 